\title{
PENA PRIVATIVA DE LIBERDADE COM TRATAMENTO PSIQUIÁTRICO E PSICOLÓGICO PARA ABUSADORES
}

Mirza Maria Pedrosa Porto de Mendonça

Doutora em Direito pela Universidad Del Museo Social Argentino. Mestra em Direito pela Pontifícia Universidade Católica de São Paulo e Professora da Universidade Católica de Pernambuco. Advogada. E-mail: mirzaporto@bol.com.br

\section{Resumo}

A pesquisa realizada teve como objetivo investigar a opinião de profissionais das áreas do direito e da saúde sobre o perfil do abusador sexual de crianças no âmbito familiar e a eficácia do tipo de penalização que ele sofre. Esse tipo de crime tem como sujeito ativo alguém que, provavelmente, não goza de sanidade mental suficiente para controlar a sua inclinação para a ilicitude, podendo ou não ser classificado como doente mental. A investigação abrange a incidência e os efeitos desse acontecimento na vida intrafamiliar. Versa sobre essa temática com o objetivo de estabelecer um novo paradigma jurídico no âmbito das penas na esfera mais particular do direito penal. $\mathrm{O}$ trabalho almeja demonstrar a relevância social do tema e a necessidade de um efetivo agasalho normativo para os abusadores sexuais, principalmente os intrafamiliares e realiza uma proposta clara de alteraçáo legislativa no que se refere a esse tipo de crime, postulando a necessidade de adequar a lei à realidade fática. Argumenta que o tratamento psicanalítico dos agressores como forma de pena é mais importante do que a simples privação da liberdade. Defende que a legislação vigente é incipiente e inadequada para esses casos, sendo esta opiniáo corroborada por um significativo número de especialistas. Não se pretende com isso defender o criminoso que pratica o abuso sexual, mas buscar soluções para a impunidade e o respeito ao princípio da individualização da pena.

\section{Palavras-chave}

Abuso sexual; Vítima; Abusador; Penalização; Tratamento.

\section{Abstract}

The research aimed to investigate the opinion of professionals in law and health areas on the profile of the sexual abuser of children within the family and the effectiveness of the type of penalty he suffers. The offender is someone who probably does not enjoy enough sanity to control its inclination to unlawful and may or may not be classified as 
mentally ill. The research covers the incidence and effects of this event on intra-family life. Deals with this issue in order to establish a new legal paradigm in the context of the penalties in the most private sphere of criminal law. The work aims to demonstrate the social relevance of the topic and the need for an effective regulatory sweater for sexual abusers, especially the intra-family and makes a clear proposal for legislative changes with regard to this type of crime, arguing the need to adapt the law the objective reality. It argues that psychoanalytic treatment of offenders as a means of punishment is more important than the simple deprivation of liberty. It argues that the current legislation is incipient and inadequate for such cases and this opinion supported by a significant number of experts. This is not to defend this criminal who practice sexual abuse, but to seek solutions to impunity and respect for the principle of individualization of punishment.

\section{Key words}

Sexual abuse; Victim; Abuser; Penalty; Treatment.

\section{Introdução}

Este artigo contempla parte dos estudos da tese EL OTRO LADO DEL ABUSO SEXUAL INTRAFAMILIAR: UN NUEVO PARADIGMA JURÍDICO (Mendonça, 2014). Versa sobre a temática do abuso sexual, com análises que visam a estabelecer um novo paradigma jurídico no âmbito das penas, na esfera mais particular do Direito Penal. Contudo, não se pretende limitar o estudo do tema, pela abrangência das situaçóes que envolvem família, sentimentos e desvios psicológicos. Assim, devido à complexidade da questão, abordará o perfil psicocriminal de agentes do abuso sexual no seio familiar e a visão sociocriminal do abusador.

O fenômeno foi visto a partir de um corte metodológico que aborda o fato do abuso restrito ao âmbito familiar, situação em que ocorre com maior frequência, independentemente de raça, credo, condição social, nacionalidade ou formação cultural.

\section{Família, os Princípios Constitucionais e o Abuso Sexual}

A organização da sociedade dá-se em torno da estrutura familiar e não em torno de indivíduos ou de pequenos grupos. Num conceito amplo, família é o organismo formado por todas as pessoas ligadas por um vínculo de sangue, ou seja, todas as pessoas originadas de um tronco ancestral comum, o que significa que, dentro dessa órbita, estão inclusos todos os parentes consanguíneos.

A família é uma realidade sociológica e constitui a base do Estado, o núcleo fundamental em que repousa toda a organização social. Trata-se de instituição necessária e 
sagrada para o desenvolvimento da sociedade como um todo e, por isso, é merecedora de ampla proteção do Estado (GONÇALVES, 2005:12).

O que prevalece no Direito de Família é seu conteúdo personalíssimo, focado numa unidade ética e social. Desse modo, caso as normas sejam violadas, poderá ocorrer a suspensão ou a extinção do poder familiar, a dissolução da sociedade conjugal, ou seja, a cessação dos direitos exercidos pelos membros de uma família entre si e na sociedade (GONÇALVES, 2005: 2). Assim, o conteúdo do Direito de Família foca no estudo acerca de casamento, união estável, filiação, alimentos, poder familiar e outros. A esse respeito, Maria Berenice Dias destaca:

O direito das famílias - por estar voltado à tutela da pessoa - é personalíssimo, adere indelevelmente à personalidade da pessoa em virtude de sua posição na família durante toda a vida. Em sua maioria é composto de direitos intransmissíveis, irrevogáveis, irrenunciáveis e indisponíveis.

(DIAS, 2009: p. 35).

\subsection{Princípios Constitucionais e Família}

Os princípios revestem-se de grande relevância, porque marcam, basicamente, todo o sistema jurídico. São as proposiçôes genéricas que informam a ciência e que proporcionam as bases valorativas sobre as quais se constrói o sistema jurídico.

O Código Civil brasileiro, buscando adaptar-se à evolução social, à boa-fé e à função social dos direitos, incorporou mudanças legislativas e trouxe consigo ampla regulamentação dos aspectos essenciais do Direito de Família à luz dos princípios e normas constitucionais, dando guarida ao princípio da dignidade da pessoa humana.

Segundo Paulo Bonavides,

"Os princípios constitucionais foram convertidos em alicerce normativo sobre o qual assenta todo o edifício jurídico do sistema constitucional, o que provocou sensível mudança na maneira de interpretar a lei”. (Apud DIAS, 2009:56).

\subsubsection{Princípio da Dignidade da Pessoa Humana}

É indiscutível a importância do princípio da dignidade humana, tanto em sentido amplo quanto em sentido mais restrito, como esteio dos sistemas jurídicos em geral e, em particular, do sistema constitucional brasileiro.

Nesta abordagem sobre a violência, suas consequências e a ingerência do poder judiciário, não se pode dissociar o enfoque dos direitos humanos, também em relação 
ao abusador, pois o agente que pratica o delito também deve ter seus direitos humanos respeitados. Isso está acontecendo? Será que a dignidade humana do abusador sexual é completamente ignorada? É fundamental que se busque uma decisão legislativa para a minimização de um problema que vem sendo ignorado pela Justiça.

Com esteio nesse entendimento, é que se pronuncia o jurista Ingo Wolfgang Sarlet:

Embora entendamos que a discussão em torno da qualificação da dignidade da pessoa humana como princípio ou direito fundamental não deva ser superestimada, já que não se trata de conceitos necessariamente antitéticos e reciprocamente excludentes, não só, mas também, pelo fato de que as próprias normas de direitos fundamentais expressamente consagrados na Constituição encontrarem - pelo menos em grande parte - seu fundamento na dignidade da pessoa humana, também é possível reconhecer que do próprio princípio da dignidade da pessoa podem e até mesmo devem ser deduzidas posiçóes jusfundamentais (direitos e deveres), ainda que expressamente positivadas, de tal sorte que, neste sentido, é possível aceitar que se trata de uma norma de direito fundamental, muito embora daí não decorra, pelo menos não necessariamente, a existência de um direito fundamental à dignidade. (SARLET, 2011:574).

Pode-se dizer que o princípio da dignidade humana é a base para a boa convivência entre os membros da entidade familiar, pois dele advieram os demais direitos de família. Importante ressaltar o respeito à dignidade humana como sendo a base de todos os direitos nacionais, uma vez que viver dignamente é respeitar os limites de cada um, a fim de proporcionar uma boa relação familiar e social.

\subsection{A Organização Familiar e a Proteção à Criança e ao Adolescente}

A família é uma entidade histórica, interligada aos rumos do desenvolvimento da humanidade, mutável na exata medida em que se modifica a cultura e a arquitetura da própria história através dos tempos. Qualquer que seja a sociedade que se queira estudar - antiga ou moderna, oriental ou ocidental -, dois polos serão sempre referidos: o econômico e o familiar.

De acordo com o entendimento de Dias (1997:35):

Cada vez mais a ideia de família se afasta da estrutura do casamento. A possibilidade do divórcio e o estabelecimento de novas formas de convívio revolucionaram o conceito sacralizado de matrimônio. A existência de outras entidades familiares e a faculdade de reconhecer filhos havidos fora do casamento operaram verdadeira transformação na própria família. Assim, na busca do conceito de entidade familiar, é necessário ter uma visão pluralista, que albergue os mais diversos arranjos vivenciais. 
Conforme Saraiva (2005:34), no Estatuto da Criança e do Adolescente-ECA, encontram-se os fundamentos dos três grandes sistemas de garantias (primário, secundário e terciário) que estabeleceram as diretrizes para uma política pública que prioriza as crianças e os adolescentes, reconhecendo a sua condição de pessoa em processo de desenvolvimento. Sáo eles:

Sistema primário - refere-se às políticas públicas de caráter universal para atendimento a toda a população infanto-juvenil brasileira sem quaisquer distinçôes (traduzido especialmente pelos arts. 4º, 86 e 87 , do ECA):

Art. 4º É dever da família, da comunidade, da sociedade em geral e do Poder Público assegurar, com absoluta prioridade, a efetivação dos direitos referentes à vida, à saúde, à alimentação, à educação, ao esporte, ao lazer, à profissionalização, à cultura, à dignidade, ao respeito, à liberdade e à convivência familiar e comunitária.

Parágrafo único. A garantia de prioridade compreende:

a) Primazia de receber proteção e socorro em quaisquer circunstâncias;

b) Precedência de atendimento nos serviços públicos ou de relevância pública;

c) Preferência na formulação e na execução das políticas sociais públicas;

d) Destinação privilegiada de recursos públicos nas áreas relacionadas com a proteção à infância e à juventude.

Art. 86. A política de atendimento dos direitos da criança e do adolescente far-se-á através de um conjunto articulado de açôes governamentais e não governamentais, da União, dos Estados, do Distrito Federal e dos Municípios.

Art. 87. São linhas de ação da política de atendimento:

I. Políticas sociais básicas;

II. Políticas e programas de assistência social, em caráter supletivo, para aqueles que deles necessitem;

III. Serviços especiais de prevenção e atendimento médico e psicossocial às vítimas de negligência, maus-tratos, exploração, abuso, crueldade e opressáo;

IV. Serviço de identificação e localização de pais, responsável, crianças e adolescentes desaparecidos;

V. "Proteção jurídico-social por entidades de defesa dos direitos da criança e do adolescente".

Sistema secundário - possui natureza preventiva e abrange as medidas de proteção dirigidas a crianças e adolescentes em situação de risco pessoal ou social, que sejam vítimas 
e cujos direitos fundamentais foram violados (especialmente os arts. 98 e 101). Essas medidas protetivas são aplicáveis às crianças e aos adolescentes vitimados.

Art. 98. As medidas de proteção à criança e ao adolescente são aplicáveis sempre que os direitos reconhecidos nesta Lei forem ameaçados ou violados:

I. Por ação ou omissão da sociedade ou do Estado;

II. Por falta, omissão ou abuso dos pais ou responsável;

III. Em razão de sua conduta.

Art. 101. Verificada qualquer das hipóteses previstas no art. 98, a autoridade competente poderá determinar, dentre outras, as seguintes medidas:

I. Encaminhamento aos pais ou responsável, mediante termo de responsabilidade;

II. Orientação, apoio e acompanhamento temporários;

III. Matrícula e frequência obrigatórias em estabelecimento oficial de ensino fundamental;

IV. Inclusão em programa comunitário ou oficial de auxílio à família, à criança e ao adolescente;

V. Requisição de tratamento médico, psicológico ou psiquiátrico, em regime hospitalar ou ambulatorial;

VI. Inclusão em programa oficial ou comunitário de auxílio, orientação e tratamento a alcoólatras e toxicômanos;

VII. Acolhimento institucional;

VIII. Inclusão em programa de acolhimento familiar;

IX. Colocação em família substituta.

(Parágrafos $1^{\circ}$. ao 12 - ver no texto oficial)

Sistema terciário - trata das medidas socioeducativas destinadas aos adolescentes em conflito com a lei por terem cometido atos infracionais, ou seja, aqueles que passam da condição de vitimizados a vitimizadores (refletido especialmente nos arts. 103 e 112 (SAPIENZA e PEDROMÔNICO, 2010:106).

Art. 103. Considera-se ato infracional a conduta descrita como crime ou contravenção penal.

Art. 112. Verificada a prática de ato infracional, a autoridade competente poderá aplicar ao adolescente as seguintes medidas:

I. Advertência;

II. Obrigação de reparar o dano;

III. Prestação de serviços à comunidade; 
IV. Liberdade assistida;

V. Inserção em regime de semiliberdade;

VI. Internação em estabelecimento educacional;

VII. Qualquer uma das previstas no art. 101, I a VI.

$\$ 1^{\circ}$ A medida aplicada ao adolescente levará em conta a sua capacidade de cumpri-la, as circunstâncias e a gravidade da infraçáo.

$\$ 2^{\circ}$ Em hipótese alguma e sob pretexto algum, será admitida a prestação de trabalho forçado.

$\$ 3^{\circ}$ Os adolescentes portadores de doença ou deficiência mental receberão tratamento individual e especializado, em local adequado às suas condiçóes.

Pela legislação brasileira, o direito à proteção especial às crianças e adolescentes abrange os aspectos relativos ao trabalho, com idade mínima de 14 anos para a admissão, aquisição de direitos trabalhistas e previdenciários; garantia de acesso do trabalhador adolescente à escola; conhecimento da atribuição de ato infracional com defesa técnica por profissional qualificado; respeito à condição peculiar de pessoa em desenvolvimento, obedecendo aos princípios da excepcionalidade na aplicação de medidas privativas de liberdade; estímulo do poder público para o acolhimento por guarda de órfãos ou abandonados; acesso a programas de prevenção e atendimento especializado aos dependentes químicos. Além disso, a lei prevê a punição contra o abuso, a violência e a exploração sexual infanto-juvenil (SARAIVA, 1999:76).

\section{0 Abuso Sexual}

De acordo com Parisotto (2001), existem quatro categorias distintas de abuso sexual: a pedofilia, o estupro, o assédio sexual e a exploração sexual profissional. Dessa forma, a psicologia caracteriza o abuso sexual pelo não consentimento da criança na relação sexual com o adulto ou em qualquer contato físico com propósito sexual. Também se considera abuso sexual a coerção ou a submissão de menor à exposição de estímulos sexuais inapropriados para a sua idade e desenvolvimento psicológico e/ou intelectual, ou a jogos de sedução afetiva perpetrados pelo abusador.

Ainda, segundo Furniss (1993:19):

O abuso sexual pode ser considerado uma Síndrome de Segredo, pois, na maioria das vezes, as crianças encontram dificuldades em revelar o que lhes aconteceu. Uma das razóes para isso é a falta de preparo de quem recebe a denúncia para lidar com o tema. [...] é necessário que o profissional tenha capacidade pessoal e profissional para lidar com o assunto, assim como uma estrutura de apoio. 
O abuso sexual contra crianças e adolescentes ocorre com uma frequência assustadora e é considerado no Brasil como um problema de saúde pública que "vitimiza". Percebe-se, pelos casos divulgados nos meios de comunicação, que o tabu, o esconderijo dos casos está sendo quebrado. Infelizmente, também pode ser percebido que a puniçáo ao abusador não está sendo adequada.

Está claro que o descaso político com relação a esses casos que atormentam a sociedade tem levado a indagaçóes a respeito da eficácia do Direito Penal e da punição que está sendo proposta para esses abusadores.

Atualmente, a violência é um dos piores problemas enfrentados pela sociedade. Manifesta-se das mais diversas formas. Embora presentes ao longo dos tempos, somente nos dias de hoje, frente à consciência da relevância dos direitos humanos, tornou-se prioridade combatê-la.

Violência é "o ato ou efeito de violentar, de empregar força física (contra alguém ou algo) ou intimidação moral contra (alguém)” (HOUAISS, 2010:866).

Pode-se afirmar que violência doméstica contra menores de idade:

"Representa todo ato ou omissão, praticados por pais, parentes ou responsáveis, contra crianças e adolescentes que - sendo capaz de causar dano físico, sexual e/ou psicológico à vítima - implica, de um lado, uma transgressáo do poder/dever de proteção do adulto e, de outro, uma coisificação da infância, isto é, uma negação do direito que crianças e adolescentes têm de serem tratados como sujeitos e pessoas em condição peculiar de desenvolvimento. (GUERRA, 1998:32).

Já a violência sexual ou a exploração sexual, conceituada genericamente, significa "o ato sexual, relação hetero ou homossexual entre adulto e criança ou adolescente, objetivando utilizá-la para obter uma estimulação sexual.” (GUERRA, 1998:32).

É também definida como:

“... envolvimento de crianças e adolescentes, dependentes e imaturos quanto ao seu desenvolvimento, em atividades sexuais que não têm condições de compreender plenamente e para as quais são incapazes de dar o consentimento informado ou que violam as regras sociais e os papéis familiares. Incluem a pedofilia, os abusos sexuais violentos e o incesto, sendo que os estudos sobre a frequência sexual violenta são mais raros do que os que envolvem violência física." (GUERRA, 1998:33).

\subsection{Abusador Sexual}

No Brasil, são poucos os estudos sobre o perfil dos abusadores, daí a necessidade de tentar defini-lo para os fins desta análise. 
O abusador, em sua grande maioria, nega o ato violento, a severidade do abuso, a natureza abusiva da ação, os efeitos prejudiciais do abuso à vítima e a responsabilização pelo crime. São pessoas que apresentam dificuldades em manter relações íntimas e dificuldades emocionais, podendo ou não apresentar quadro patológico definido.

Segundo Moura (2007), o vitimizador sabe que seu ato é errado e, aparentemente, não consegue controlar-se, entretanto o abuso não gera prazer ao abusador, e sim alívio da ansiedade. Geralmente, são compelidos à repetição.

$\mathrm{O}$ abusador pode ser violento, porém quase sempre usa a violência de forma silenciosa ou velada, no entanto, sente medo e negará o abuso quando denunciado. A mesma autora refere que o maior dano à criança é a concretização de suas fantasias sexuais, que deveriam permanecer em seu imaginário.

Quando ocorre dentro do seio familiar (o abusador é o pai ou padrasto, por exemplo), o processo é bastante complicado. Normalmente, interna-se a criança para sua proteção, e toda uma equipe trabalha com o clareamento da situação. Por vezes, o abusador espanca a criança e esta necessita ser tratada fisicamente. A família se divide entre os que acusam o abusador e os que acusam a vítima, culpando esta última pela participação e provocação do abuso. O tratamento, então, é inicialmente direcionado para a intervenção em crise (JARDIM, 2009:92). O abusador, a vítima e a família devem ser tratados a longo prazo. É evidente que o fato de o abuso de crianças ser um crime, o tratamento do abusador torna-se mais difícil. Por isso, deve ser feito em paralelo com a pena.

Assim, ao acusar o agente, a principal sanção que a população anseia é a prisão, quando não aspira à castração química. É crença errônea, arraigada na consciência do povo brasileiro, a de que somente a prisão configura a resposta penal. A pena privativa de liberdade, quando aplicada genericamente a crimes grave e leves, o que Michel Foucault chamaria de punição generalizada (apud. BECCARIA:69), só intensifica o drama carcerário e não reduz a criminalidade, com um agravante: a precariedade dos estabelecimentos prisionais no Brasil propicia o convívio indistinto de pessoas de periculosidades diversas, constituindo-se estes em autênticas universidades do crime organizado, onde os detentos assimilam as sofisticadas condiçóes e técnicas voltadas para a prática criminosa.

Segundo Zaffaroni, “a ressocialização está longe de ser objetivo da pena de prisão. Perdeu-se muito a bússola da ressocialização não sendo mais possível considerá-la utopia, algo irrealizável ou algo absurdo, aquilo que jamais poderá ser feito porque está em oposição à lógica”. (ZAFFARONI, 2004:31)

A problemática do abuso sexual, principalmente o interfamiliar, não pode ser restrita ao ponto de vista jurídico. É um assunto a ser esclarecido com apoio de outras áreas do conhecimento, a fim de que o juiz possa julgar de acordo com o princípio da verdade real, fundamentado pela equidade. Muitas são as tentativas de compreensão teórica do abuso 
sexual, de seu causador e da situação dessa violência dentro de um contexto mais amplo, o que requer uma abordagem interdisciplinar. $\mathrm{O}$ vitimizador deveria receber acompanhamento terapêutico com profissionais da área de saúde mental, tais como psicólogos e psiquiatras, e não ficar apenas relegado à aplicação de uma pena que limite sua liberdade.

A maioria dos agressores são pessoas comuns que mantêm preservadas as demais áreas da personalidade, defende Lencarelle (2002:60). Podem ser bons profissionais e ter destaque na sociedade. Trata-se, no entanto, de pessoas perversas, que utilizam estratégias e disfarces, mostrando-se muitas vezes autoritárias ou moralistas.

Outro ponto observado por Lencarelle é que há possibilidades de evoluir de uma situação de abusado (a) a abusador (a) na idade adulta, em decorrência da prática sexual precoce e suas implicaçóes psicológicas, permanecendo com isso na cena traumática da agressão sexual (LENCARELLI ${ }^{1}, 2002: 61$ ).

Segundo Alberto França Jardim, existem quatro tipos de abuso sexual: pedofilia, estupro, assédio sexual e exploração sexual profissional. Seja qual for o tipo de abuso perpetrado, há necessidade de tratamento tanto dos abusadores, quanto das vítimas.

Diante dos objetivos do artigo, tratar-se-á dos abusadores sexuais intrafamiliares.

As causas do abuso são variáveis. O molestador geralmente justifica seus atos, racionalizando que está ofertando oportunidades à criança de desenvolver-se no sexo, ser especial e saudável, inclusive praticando sexo com a permissão desta. Como ressalta JARDIM (2009:91), pode envolver-se afetivamente e não ter qualquer noção de limites entre papéis ou de diferenças de idade.

Cabe sintetizar, um dos tipos de classificação estabelecido por autores que tratam da matéria:

a) Pedófilo abusador:

O tipo mais comum de pedófilo abusador é o indivíduo imaturo.

\section{b.1.1) Pedófilo molestador}

A característica marcante do pedófilo molestador é o padrão de comportamento invasivo com utilização frequente de violência. Tem prazer imenso em seduzir, diminuindo, assim, seus problemas com a baixa autoestima, que provavelmente o acometem, e mantém várias vítimas seduzidas em estágios diferentes, esperando sua ação. A internet é um meio de busca de alvos bastante comum para esse tipo de agressor, cujo comportamento sexual é composto de sexo oral e vaginal. O uso de pornografia infantil melhora seu desempenho e a conquista da vítima. É frequente

1 Disponível em: http://www.abrapia.org.br/antigo/textos/ Artigos/O perfil psicológico do abusador.htm 
esse tipo de molestador infantil colecionar filmes caseiros e/ou fotografias das crianças que foram suas vítimas;

b.1.2) Molestador situacional inescrupuloso (moral ou sexual) -

Esse agressor abusa de quem está disponível para satisfazer suas necessidades sexuais e o fato de atacar crianças faz parte desse contexto, não sendo a sua prioridade;

b.1.3) Molestador situacional inadequado -

Alguns autores enfatizam a possibilidade de que esse tipo de molestador sofra de alguma forma de transtorno mental (retardo mental, senilidade etc.) que o impossibilita de perceber a diferença entre certo e errado em suas práticas sexuais, ou seja, o caráter delituoso de seus atos;

b.2) Pedófilo molestador preferencial -

Para o molestador desse grupo, a gratificação sexual só será alcançada se a vítima for uma criança. A característica marcante desse tipo de molestador é a violência extrema, que chega até o homicídio. Ele pode ser do tipo: sedutor, sádico e introvertido;

b.2.1) Pedófilo molestador preferencial sedutor, esse perfil representa um dos grupos mais perigosos, visto ser difícil para a criança escapar das suas máos. Geralmente ele corteja, presenteia e seduz seus alvos e é capaz de percorrer qualquer distância para alcançá-los;

b.2.2) Pedófilo molestador preferencial sádico -

Esses agressores pretendem molestar crianças com o expresso desejo de machucá-las. Seu excitamento sexual é diretamente proporcional à violência, que pode ser fatal.

b.2.3) Pedófilo molestador preferencial introvertido -

É um indivíduo que prefere crianças, mas não tem habilidade pessoal para seduzi-las. Tipicamente, mantém mínima comunicação verbal com a criança que escolhe."2.

O seio da família é profundamente atingido pelo vitimizador sexual. Quem é esse vitimizador? O que o leva a abusar sexualmente dos seus entes?

Como fruto de investigação, destaca-se o perfil do abusador, visto por GUTIERREZ:

"El abusador sexual dentro de la família, de manera notable, assumirá un papel dominante, de neto corte autoritário, imponiendo una rígida

2 SERAFIM, Antonio de Pádua, SAFFIL, Fabiana, RIGONATTI Sérgio Paulo, CASOY Ilana, BARROS, Daniel Martins, Perfil psicológico e comportamental de agressores sexuais de crianças, Disponível em: http://www.hcnet.usp.br/ipq/revista/vol36/n3/pdfs/105.pdf, acesso em: 21 de junho de 2013. 
disciplina, a fuerza de golpes, vejaciones e castigos. Sin embargo, también como constante, sulen verse evidentes distinciones de trato, entre hijos e hijas, abusados o no sexualmente, recibie las primeras prebendas o pseudo privilégios (en cuanto a alimentacíon, vestimenta, salidas con el abusador, y liberdades, dentre de la dinâmica de família, etc.). El sujeto intenta praticar um eficaz control sobre la vida de los demás. Aparecen como indivíduos de marcada rigidez, meramente superficial, profundamente infelices y solitários, cerrados, inclusive a mantener amistad com otras personas (conocidos de su trabajo o actividad, por ejemplo).” (GUTIERREZ. 2007:57)

A ausência de uma preocupação mais específica com a identificação do caráter e das condutas do vitimizador, dos significados atribuídos por ele à prática da violência, caracteriza negligência e omissão das políticas públicas no sentido de prevenir a reincidência desse tipo de delito, de favorecer a ressocialização do abusador e de alcançar a cura, vez que existe essa possibilidade, em alto percentual, conforme afirma o psicodramaticista Maher Musleh (2008).

A maioria das pessoas, ao ouvirem a expressão "abusador sexual", geralmente tem a imagem de uma pessoa "diferente" , um "tarado", um "depravado", um "escroque doméstico", uma "besta", um "bicho", uma pessoa esquisita, cheia de hábitos estranhos. No entanto, essa ideia não corresponde à realidade. As criaçôes imaginárias e preconcebidas pelo grupo social com referência ao aspecto do abusador são equivocadas, uma vez que, regra geral, o abusador sexual é uma pessoa que tem aparência comum, é socialmente adequada, um verdadeiro cavalheiro e, por que não dizer, um sedutor.

Colocando em destaque o último adjetivo (sedutor) referente ao abusador, torna-se importante relatar trechos de uma conversa com um médico psicanalista, responsável pelo acompanhamento de um abusador sexual intrafamiliar:

M.S.

"Tive a oportunidade de atender a um abusador apenas. Ele era de classe média. Foi em hospital da rede púbica. Ele era um sedutor. Com a continuidade das sessôes ele começou a ter uma postura de quem pretendia me seduzir; relatei a conduta em reunião de grupo de profissionais. Náo tive condiçóes de continuar a atendê-lo. Náo tenho como diagnosticar. Relatou durante uma das sessóes que havia sido abusado na infância."

$\mathrm{Na}$ tese, afirma-se, com segurança, que o vitimizador pode pertencer a qualquer classe social, e ter elevado grau de instrução. Pode o abusador ter alto poder aquisitivo, e ser encontrado entre médicos, autoridades, empresários, professores e outros, sendo descabido o conceito de que o abuso sexual intrafamiliar só é perpetrado por pessoas de baixa renda, ou pouco intelectualizadas. 
Na prisão, tida como uma verdadeira máquina deteriorante, o vitimizador está exposto a uma marginalização social e, sem condições adequadas de ressocialização, há a certeza da reincidência, uma vez que não recebem identificação de suas enfermidades e, muito menos, o tratamento adequado para uma reabilitação mental.

\subsection{Um Problema Social}

É fundamental compreender que não é possível apenas pensar utopicamente em um mundo mais igualitário e justo. É necessário transformar o sonho em realidade coletiva, enfrentando a situação de violência sexual intrafamiliar, que emerge nas sociedades pósmodernas, apesar de sempre ter existido no curso da história. É preciso sair do silêncio e tornar pública essa questão. Afinal de contas, trata-se de um problema que pode afetar a vida de cada um e deve ser pensado por todos. É necessário ainda assegurar direitos, respeito à dignidade, em todas as vertentes.

A violência sexual intrafamiliar causa danos físicos, emocionais, morais, espirituais. Infelizmente, são observados apenas os seus efeitos e consequências causados às vítimas. Não há verificação das causas ou do perfil dos causadores.

As famílias têm diferentes histórias, realidades socioeconômicas e culturais. Cada uma tem o seu jeito próprio de viver. Consequentemente, a violência intrafamiliar assume as mais variadas formas. Essa característica torna impossível generalizar o abuso sexual praticado no seio das famílias. Não é possível, portanto, atribuir causas idênticas e penalidades semelhantes aos abusadores. Nesse tipo de prática, a penalidade aplicada deve observar a conduta do agente, para identificar o tipo de tratamento a ser imputado ao mesmo.

Ao se encarar o papel social, político e jurídico do Estado, chega-se à conclusão de que a prisão é uma instituição falida, uma violação aos direitos humanos, o que pode ser facilmente observado com a crescente violência na sociedade brasileira, principalmente com relação aos crimes de abuso sexual. Os abusadores sexuais, em sua grande maioria, são portadores de parafilias e até mesmo, em alguns casos, são inimputáveis, mas não recebem os exames e o tratamento adequado para seus casos. Simplesmente, são jogados no cárcere.

O abusador intrafamiliar, na figura do pai ou daquele que assume a autoridade paterna, em algumas situaçóes, quando da prática do abuso, manifesta pulsóes sádicas, violentas e suas relações sexuais são atuadas numa confusão entre uma criança e um adulto. Ele pode ser considerado na maior parte do tempo como um pai "incestuoso", "fiel à família” ou pedófilo.

O pedófilo já tem diagnóstico próprio, está incluído na Classificação Internacional de Doenças, (CID 10 e DSM 4) no item F65, que trata dos transtornos da preferência 
sexual, como "preferência sexual por crianças", quer se trate de meninos ou meninas, geralmente pré-púberes ou no início da puberdade, embora não seja um louco, em virtude de ter consciência do que faz, é portador de grave desvio sexual, de uma desordem distintivamente moral.

A pedofilia não é crime, o que demonstra a real necessidade de se definir o que é pedofilia e todas as suas características, bem como a sua relação com o Direito brasileiro. Etimologicamente, pedofilia é a junção de radicais de origem grega: paidos é criança ou infante, e phila, amizade, amor (TRINDADE; BREIER, 2010:21). Assim sendo, poderse-ia conceituar o pedófilo como aquele que ama a criança.

Observando-se a conceituação atribuída à pedofilia, entende-se que o indivíduo, por ser portador do transtorno da preferência sexual, ao saciar suas perversóes sexuais, atendendo aos seus impulsos, interfere na esfera particular de outras pessoas, podendo causar graves danos não apenas a si mesmo, mas ao grupo social.

Não é pelo fato de ser portador de um distúrbio que o pedófilo se torna um criminoso. Seus sentimentos pela criança podem apenas ficar no plano das fantasias, o que o colocaria na categoria de pedófilo passivo. Entretanto, se em virtude de seu impulso irresistível, tendo em vista a sua psicopatologia, abusa sexualmente de uma criança (pedófilo ativo), sua conduta será tipificada como um delito penal e, consequentemente, responderá pela prática do delito.

\subsection{Terapia para os Abusadores}

Apesar de não se poder afirmar que existe cura para a pedofilia, uma parcela considerável de pedófilos responde aos tratamentos, que se têm mostrado cada vez mais eficazes. Pedófilos e abusadores sexuais de crianças são pessoas que precisam ser tratadas, para que abusos não cheguem a acontecer ou para prevenir novos episódios. Ou seja, os pedófilos e abusadores necessitam ser tratados para o bem das crianças, da sociedade e deles mesmos (TRINDADE, 2010:114). SPIZIRRI, (2008:33) ressalta que o tratamento, nos casos do abusador sexual, deve ser não apenas a psicoterapia, mas o acompanhamento por toda a vida, com antidepressivos, antipsicóticos e estabilizadores de humor, objetivando ajudar o abusador a controlar o impulso agressivo, que pode ser aumentado com a presença da ansiedade.

\section{Legislação}

Os abusadores, quando punidos pelo encarceramento, não recebem qualquer atenção no que diz respeito a algum tipo de diagnóstico que identifique e trate possíveis distúrbios psíquicos. Muitas vezes, são pessoas excluídas da sociedade, que não tiveram 
condiçốes de se desenvolver emocionalmente de forma saudável. São frutos das suas histórias e dos lugares que ocuparam na família e na vida.

\subsection{Crime de Estupro de Vulnerável}

Embora a pedofilia não seja crime e o abuso sexual contra criança possa em alguns casos ser voluntarioso, ou seja, a criança consentiu com o ato, percebe-se que o legislador brasileiro tipifica tal conduta como criminosa:

Art. 217-A $\mathrm{A}^{3}$ Ter conjunçấo carnal ou praticar outro ato libidinoso com menor de 14 (catorze) anos: (Incluído pela Lei no 12.015, de 7 de agosto de 2009)

Pena - reclusão, de 8 (oito) a 15 (quinze) anos.

$\$ 1^{\circ}$ Incorre na mesma pena quem pratica as açóes descritas no caput com alguém que, por enfermidade ou deficiência mental, não tem o necessário discernimento para a prática do ato, ou que, por qualquer outra causa, não pode oferecer resistência.

$\$ 2^{\circ}(\mathrm{VETADO})$

$\$ 3^{\circ}$ Se da conduta resulta lesão corporal de natureza grave: (Incluído pela Lei $n^{\circ} 12.015$, de 7 de agosto de 2009)

Pena - reclusão, de $10(\mathrm{dez})$ a 20 (vinte) anos. (Incluído pela Lei $\mathrm{n}^{\circ}$ 12.015, de 7 de agosto de 2009)

$\$ 4^{\circ}$ Se da conduta resulta morte: (Incluído pela Lei $\mathrm{n}^{\circ} 12.015$, de 7 de agosto de 2009)

Pena - reclusão, de 12 (doze) a 30 (trinta) anos.

O Código Penal brasileiro não estende a proteção dada ao menor de 14 anos ou vulnerável à pessoa maior de 14 e menor de 18 anos. Em sua defesa, somente se pode utilizar a tipificação de estupro, situação que foge à realidade, uma vez que pode ocorrer abuso sexual sem violência ou grave ameaça.

Em 2009, o legislador, preocupado com os crescentes abusos sexuais intrafamiliares e com o fato de a legislação brasileira sobre crimes sexuais estar ultrapassada, provocou uma reforma no Código Penal, abolindo tipos penais até então existentes, tais como o adultério e trazendo novas figuras como o estupro de vulnerável.

Em decorrência dessas novas preocupaçóes e anseios, a partir de uma iniciativa da CPMI - Comissão Parlamentar Mista de Inquérito, da Exploração Sexual de Crianças e Adolescentes -, produziu-se o Projeto de Lei do Senado no. 253 de 2004. Promulgada em

3 CÓDIGO PENAL BRASILEIRO: Disponível em www.senado.gov.br, acesso em 14 de agosto de 2013. 
07 de agosto daquele ano, a Lei 12.015 traz vultosas alteraçóes, com especial destaque ao Título VI do Código Penal, anteriormente denominado "Dos Crimes Contra os Costumes", que passou a denominar-se "Dos Crimes Contra a Dignidade Sexual”.

A nova Lei surgiu de uma iniciativa da CPMI (Comissão Parlamentar Mista de Inquérito) da Exploração Sexual de Crianças e Adolescentes, que, juntamente com o Ministério da Justiça, a Secretaria Especial de Direitos Humanos, o Ministério Público do Trabalho, o Ministério Público Federal, a Defensoria Pública da União, e a Organização Internacional do Trabalho, deu origem ao Anteprojeto de Lei que, por sua vez, forneceu os parâmetros basilares para a formação do Projeto de Lei no ${ }^{\circ} 253$ de 2004 do Senado Federal, cujo objetivo seria justamente a criação da nova Lei (GRECO, 2010:625).

Os crimes sexuais em alguns casos são considerados crimes hediondos, como os crimes de estupro que foram assim definidos, em 2012, pelo Superior Tribunal de Justiça, por decisão unânime. Independente da forma em que forem praticados, entendendo que o bem violado é a liberdade sexual, deve quem o pratica iniciar o cumprimento da pena em regime fechado.

Mas a reforma do corpo normativo não adianta se não forem reestruturadas as formas de ressocialização e de assistência social e jurídica aos agentes. $\mathrm{O}$ cárcere se configura como uma afronta à dignidade da pessoa humana, não devendo ser, portanto, alternativa para a solução desse tipo de conflito. Os agentes condenados por crimes sexuais devem ser tratados não como criminosos, e sim como pessoas portadoras de transtornos psíquicos e que, por isso, oferecem riscos à sociedade.

No Brasil, no estado de Minas Gerais, segundo Sousa (2010:8), passará a existir, no Hospital das Clínicas da Universidade Federal de Minas Gerais - HC UFMG, o centro de estudos e atendimento de abuso sexual, em um ambulatório que irá atender os abusadores. "Pela primeira vez em Minas Gerais, o pedófilo irá receber tratamento para o transtorno de preferência sexual, um distúrbio que integra a classificação internacional de doenças". Até então, a única experiência de tratamento no Brasil é feita no Instituto de Psiquiatria da Universidade de São Paulo - USP, através do Núcleo de Estudos e Pesquisa em Psiquiatria Forense e Psicologia Jurídica (NUFOR).

\section{Conclusões}

O paradigma atual de que apenas as vítimas devem ser tratadas e de que o olhar do estado deve ser direcionado para aqueles que sofreram o abuso precisa ser quebrado e substituído pelo olhar sobre todos os envolvidos, propiciando um benefício para toda a sociedade. É necessário estabelecer um novo paradigma que demande tratamento para 
todos os que sofreram as consequências da experiência do abuso sexual que estabeleça, de forma legislativa, a obrigatoriedade do tratamento para todos os abusadores, assim como se faz com os abusados.

Defende-se o acompanhamento psicológico e psiquiátrico em todas as fases e não apenas durante ou após o curso processual. Desde a fase policial, desde o momento do registro do fato, é de suma importância uma perícia psicológica criteriosa, realizada por profissional capacitado para identificar as particularidades do caso e para encaminhar o abusador, já na fase investigatória, ao tratamento adequado.

Busca-se a criação de medidas específicas para a elaboração de uma nova legislação, que seja eficaz e estabeleça a unidade de parâmetros para o trabalho dos profissionais de saúde mental e dos operadores do Direito.

A proposta aqui apresentada náo pretende solucionar a problemática do tema com a simples criação de uma lei, de regulamentação do fato pela norma. Ela vai mais além, ao deixar transparente que essa modificação da lei em vigor é uma necessidade premente da sociedade. Propóe ser este o início de um processo que se desenvolverá na efetiva realização dos princípios regentes no país, no tocante à dignidade dos cidadãos, à ausência de preconceitos e à igualdade. Em sentido amplo, propóe-se tratar os iguais de forma igual e os diferentes de forma diferente, parafraseando Aristóteles. Dessa forma, espera-se que venha a emergir um novo paradigma jurídico, fundado em princípios basilares e pré-existentes de Justiça, lançando-se um olhar diferente para a pessoa do abusador sexual.

\section{Referências}

BEE, Helen. O ciclo vital. Ed. Artes Médicas, Rio de Janeiro, 1997.

BECCARIA, Cesare. Dos delitos e das penas. Tradução de José Cretella Jr. e Agnes Cretella. 2. ed. São Paulo: Revista dos Tribunais. 2001.

DIAS, Maria Berenice. Manual de direito das famílias. 5. ed. São Paulo: Revista dos Tribunais, 2009.

A família como palco da violência sexual. : Ed. Cadernos CAES, 1997.

Incesto e alienaçáo parental/coordenadora Maria Berenice Dias. 3a ed. São Paulo. Ed. Revista dos Tribunais, 2003.

ESTATUTO DA CRIANÇA E DO ADOLESCENTE, Disponível em: www.senado. gov.br.

FURNISS T. Abuso sexual da criança: uma abordagem multidisciplinar. Manejo, terapia e intervenção legal integrados. Porto Alegre: Artes Médicas;1993.

GONÇALVES, Carlos Roberto. Direito civil brasileiro: direito de família. v.6, São Paulo: Saraiva, 2005. 
GRECO, Rogério, Código Penal Comentado. Editora Impetus, 2010.

GUERRA, Viviane Nogueira de Azevedo. Violência de pais contra filhos: a tragédia revisitada. 3. ed. São Paulo: Cortez, 1998.

GUTIÉRREZ, Pedro A. Delitos sexuales sobre menores. $1^{\text {a }} \mathrm{ed}$. Buenos Aires. La Rocca. 2007.

HOUAISS, Antônio; VILLAR, Mauro de Salles; FRANCO, Francisco Manoel de Mello. Dicionário Houaiss da língua portuguesa. Rio de Janeiro: Objetiva, 2001.

LENCARELLI, Ana Maria Brayner. O perfil psicológico do abusador sexual de crianças. Disponível em: http:/www.abrapia.org.br/antigo/textos/ artigos/O\%20perfil\%20 psicologico\%20do\%20abusador.htm

MANTEGAS, Bruno. Castração para violadores e pedófilos. 2010. Disponível em: http://www.dn.pt/inicio/interior.aspx?content_id=588899. Acessado em: outubro de 2010.

MENDES, Adriana O. Educaçáo em direitos bumanos no programa de proteçáo às crianças e adolescentes ameaçados de morte do Distrito Federal (PPCAAM-DF). Trabalho de Conclusão de Curso de Especialização em Direitos Humanos - Universidade Católica de Brasília. Brasília, 2009.

MOURA, A. da S. A criança na perspectiva do abusador sexual. Dissertação de mestrado não publicado, Instituto de Psicologia. Mestrado em Psicologia, Universidade Federal do Rio Grande do Sul. Disponível em <www.msmidia.com/cepsua/andreina.com>, 2007.

MAHER Hassan Musleh. Ampliando a Compreensão Sobre os Autores do Abuso Sexual. Disponível em: http://www.promenino.org.br, 2008.

SAPIENZA, Graziela e PEDROMÔNICO, Márcia Regina Marcondes. Risco, proteçáo e resiliência no desenvolvimento da criança e do adolescente. Editora Forense, 1999.

SARAIVA, João B. C. Adolescente e ato infracional. Porto Alegre: Livraria do Advogado Editora, 1999.

SARLET, Ingo Wolfgang. O Princípio da Dignidade da Pessoa Humana e os Direitos Fundamentais. 2. ed. Porto Alegre: Livraria do Advogado, 2002.

SOUSA, Ana. Uma doença chamada Pedofilia. Disponível em: www.diganaoaerotizacaoinfantil.wrodpress.com

SPIZIRRI, Giancarlo. Pedofilia - Consideraçóes atuais. Diagnósticos e tratamento. V-15, n, 1, janeiro-maio 2010. Pag. 33. 
TRINDADE, Jorge; BREIER, Ricardo. Pedofilia: aspectos psicológicos e penais. 2. ed. Porto Alegre: Livraria do Advogado Editora, 2010.

ZAFFARONI, Eugênio Raul; BATISTA, Nilo; ALAGIA, Alejandro; SLOKAR, Alejandro. Direito Penal Brasileiro: Teoria Geral do Direito Penal. 3v. 2.ed. Rio de Janeiro: Revan, 2003.

ZAFFARONI, Eugenio Raúl, Em busca das penas perdidas: a perda de legitimidade do sistema penal. Tradução de Vânia Romano Pedrosa e Amir Lopez Conceição. 5. ed. Rio de Janeiro: Editora Revan, 2004.

ZAFFARONI, Eugenio Raul; PIERANGELI, José Henrique, Manual de Direito Penal Brasileiro - Parte Geral - Vol. 1, 2012 Editora: Rt. 